\title{
HYDROGEN EMBRITTLEMENT ANALYSIS IN A CrMOV STEEL BY MEANS OF SENT SPECIMENS
}

\author{
G. Álvarez*, A. Zafra, F.J. Belzunce, C. Rodríguez \\ SIMUMECAMAT Research Group, University of Oviedo, Edificio Departamental Oeste, 7.1.17. Campus \\ Universitario, 33203 Gijón, Spain. \\ *Corresponding author e-mail: galvarezdiaz4@gmail.com
}

\begin{abstract}
In this study, single-edge notched tensile (SENT) specimens machined from a quenched and tempered $\mathrm{CrMoV}$ steel plate were hydrogen pre-charged using two different methods: in a high pressure and high temperature hydrogen reactor $\left(19.5 \mathrm{MPa}\right.$ and $\left.450^{\circ} \mathrm{C}\right)$; and using an electrochemical method $\left(2 \mathrm{M} \mathrm{H}_{2} \mathrm{SO}_{4}+\right.$ $0,25 \mathrm{~g} / \mathrm{l} \mathrm{As}{ }_{2} \mathrm{O}_{3}$, under a current density of $2 \mathrm{~mA} / \mathrm{cm}^{2}$ ). The thickness of the specimens was only $1 \mathrm{~mm}$ in order to facilitate hydrogen entrance in a short time and the fracture $\mathrm{J}$ resistance curves were obtained using digital image correlation (DIC) to measure crack growth. The effect of both hydrogen pre-charged methods on the fracture toughness results was analysed, as was the influence of the applied displacement rate. Embrittlement indexes increase as the displacement rate decreases, with maximum embrittlement indexes of $20 \%$ and $84 \%$ being respectively measured for gaseous and cathodic pre-charging in tests performed at a displacement rate of $0.01 \mathrm{~mm} / \mathrm{min}$. Significant differences in the operative failure micromechanisms in the samples pre-charged via both methods were also detected and hydrogen embrittlement theories (hydrogen-enhanced localized plasticity, HELP, and hydrogen-enhanced decohesion, HEDE) were evaluated by mapping the strain distribution in the crack tip process region by means of DIC.
\end{abstract}

KEYWORDS: Hydrogen embrittlement, SE(T), J-R curves, hydrogen pre-charging, DIC.

\section{INTRODUCTION}

The study of the hydrogen embrittlement phenomenon has increased in recent years. Several variables and problems come into play when a steel structure may need to work in contact with pure hydrogen or with atmospheres that contain hydrogen [1]. These situations are very common in pipes, vessels and off-shore structures [2-4]. As these structures are exposed to high loads, they may be constructed with materials with high mechanical properties, but it is also well known that hydrogen embrittlement increases with material strength [5-7].

The best technique to evaluate hydrogen embrittlement in structural steels and to obtain industrial solutions as a function of service conditions has yet to be established. Some authors use slow strain rate tension tests in different hydrogen environments [8-10], permeation tests [11-13], fracture toughness tests [14-16], fatigue crack propagation tests [17-19] or small punch tests [20-22]. According to previous research, the presence of a crack in the specimen $[23,24]$ and the decrease in the displacement test rate are important variables that increase the embrittlement of steels.

There are also two different ways to mechanically test samples under hydrogen: loading the sample at the same time as hydrogen is introduced (external hydrogen); and conducting the mechanical test after hydrogen has been pre-charged (internal hydrogen). The former methodology requires the use of very costly infrastructures that are not easily available. When the latter methodology is preferred, the hydrogen charging method is an important issue that also affects embrittlement. The two most widely-recognized pre-charging techniques are the use of gaseous pure hydrogen under high pressure and temperature [25$27]$ and electrolytic pre-charging from an aqueous acid medium under a certain current density [28,29].

Electrolytic methods are cheaper than using pure hydrogen atmospheres under high pressure, but their use is unsuitable when the thickness of the specimen is high, due to the very long time needed to charge the sample (especially when hydrogen diffusion coefficient is low) in order to reach a homogeneous hydrogen concentration [30]. In this case, which corresponds to typical standard testing specimens, the introduction of hydrogen from a gaseous atmosphere is the most reasonable method. In the present paper, pre-cracked single-edge notched samples (SENT) with a thickness of $1 \mathrm{~mm}$ submitted to slow displacement rates and 
using both aforementioned pre-charging methods (gaseous and electrolytic) were used to determine the fracture toughness of a $2.25 \mathrm{Cr} 1 \mathrm{MoV}$ quenched and tempered steel. The main aim of the study was to compare the effect of the pre-charging methods on hydrogen embrittlement. The results were compared with tests previously performed on compact tensile (CT) specimens [31]. The influence of the applied displacement rate was also analysed. Finally, the strain distribution ahead of the crack was measured during the different tests and the failure surfaces of all the samples were studied under a scanning electron microscope to differentiate the operative fracture micromechanisms.

\section{MATERIALS AND EXPERIMENTAL PROCEDURE}

\subsection{Materials}

The material used in this study was a $2.25 \mathrm{Cr} 1 \mathrm{Mo0} .3 \mathrm{~V}$ steel (SA 542 Grade D-Class 4) received as a 108 $\mathrm{mm}$ thick plate. It was normalized at $925^{\circ} \mathrm{C}$ for 30 minutes, quenched in water and tempered at $720^{\circ} \mathrm{C}$ for 3 hours. Table 1 shows the chemical composition of the steel. Microstructural analysis revealed a mixture of tempered bainite and tempered martensite with most of the carbides precipitated at internal boundaries, as can be seen in Fig. 1.

Table 1. Chemical composition of the steel (\% by weight)

\begin{tabular}{ccccccc}
\hline $\mathrm{C}$ & $\mathrm{Mn}$ & $\mathrm{Si}$ & $\mathrm{Cr}$ & $\mathrm{Ni}$ & Mo & $\mathrm{V}$ \\
\hline 0.15 & 0.52 & 0.09 & 2.27 & 0.19 & 1.06 & 0.30 \\
\hline
\end{tabular}

The tensile characterization of the steel showed it to be an isotropic material with the same properties in the three main directions of the plate. Its mechanical properties are given in Table 2, where: $E$ is the elastic modulus; $\sigma_{0}$, the yield strength; and $\sigma_{u}$, the ultimate tensile strength. The values of the coefficients $n$ and $\alpha$ of the constitutive plastic law (Eq. 1) are also shown in Table 2.

$$
\frac{\varepsilon_{p l}}{\varepsilon_{0}}=\alpha \cdot\left(\frac{\sigma}{\sigma_{0}}\right)^{n}
$$

where: $\varepsilon_{p l}$ is the plastic strain; $\varepsilon_{0}$, the strain corresponding to the yield strength; and $\sigma$, the applied stress.

Table 2. Tensile test properties (mean \pm standard deviation). Results correspond to three individual tests.

\begin{tabular}{ccccc}
\hline $\mathrm{E}(\mathrm{GPa})$ & $\sigma_{0}(\mathrm{MPa})$ & $\sigma_{\mathrm{u}}(\mathrm{MPa})$ & $\mathrm{n}$ & $\alpha$ \\
\hline $209 \pm 2$ & $590 \pm 9$ & $700 \pm 11$ & $10 \pm 0.32$ & $1.05 \pm 0.05$ \\
\hline
\end{tabular}

The standard fracture characterization of the steel was performed by Peral et al. [31] in accordance with the ASTM 1820 standard [32], using compact tensile (CT) specimens with a width of $25 \mathrm{~mm}$ and a net thickness of $10 \mathrm{~mm}$. Table 3 shows the values of the $J_{0.2}$ parameter (the $J$ initiation parameter calculated for an effective crack growth of $0.2 \mathrm{~mm}$ ) determined on specimens tested in air at room temperature (RT) and after being hydrogen pre-charged in a high pressure hydrogen atmosphere (under a pressure of 195 bar at $450^{\circ} \mathrm{C}$ for 21 hours). Table 3 also shows the effect of the displacement rate applied to these pre-charged specimens. The embrittlement produced by the presence of internal hydrogen, as well as the effect of the test displacement rate, can be better appreciated by means of the so-called hydrogen embrittlement index, HEI (Eq. 2). This index compares the value of any mechanical property tested without hydrogen (in this case, $\left.J_{0.2}\right)$ with the value determined under internal hydrogen when it is tested at a certain test rate, $J_{0.2}^{H}(v)$.

$$
\operatorname{HEI}(\%)=\frac{J_{0.2}-J_{0.2}^{H}(v)}{J_{0.2}} \cdot 100
$$

The results, shown in Table 3, reveal an embrittlement index of between 19\% and 38\% for this geometry and hydrogen pre-charging method. The influence of the applied displacement rate on the decrease in the fracture toughness of the steel is also evident. 
Table 3. Fracture toughness results and embrittlement indexes due to the presence of internal hydrogen, CT specimens [31]

\begin{tabular}{ccc} 
Condition & $J_{0.2}\left(\mathrm{~kJ} / \mathrm{m}^{2}\right)$ & $H E I(\%)$ \\
\hline As-received $\mathrm{v}=1 \mathrm{~mm} / \mathrm{min}$ & 672 & - \\
\hline Pre-charged with gaseous $\mathrm{H}_{2} \cdot \mathrm{v}=1 \mathrm{~mm} / \mathrm{min}$ & 542 & 19 \\
\hline Pre-charged with gaseous $\mathrm{H}_{2} . \mathrm{v}=0.1 \mathrm{~mm} / \mathrm{min}$ & 420 & 38 \\
\hline Pre-charged with gaseous $\mathrm{H}_{2} . \mathrm{v}=0.01 \mathrm{~mm} / \mathrm{min}$ & 448 & 33 \\
\hline
\end{tabular}

\subsection{Experimental procedure used to test the SENT specimens}

In order to obtain the thin, cracked geometry of the SENT specimen, a $25 \mathrm{~mm}$ wide by $15 \mathrm{~mm}$ thick SENB specimen was first machined. After being fatigue pre-cracked to a crack length-to-width ratio $a / W=0.5$, the specimen was finally sliced into $1 \mathrm{~mm}$ thick samples.

These thin SENT specimens were tested at RT under three different test conditions: as-received (without hydrogen), pre-charged in high pressure, high temperature gaseous hydrogen, and electrolytically or cathodically pre-charged. The hydrogen pre-charged specimens were also tested at two different displacement rates: $0.1 \mathrm{~mm} / \mathrm{min}$ and $0.01 \mathrm{~mm} / \mathrm{min}$.

Gaseous pre-charging was carried out in an autoclave, using the same charging conditions as those employed by Peral et al. [31]: 195 bar of pressure at $450^{\circ} \mathrm{C}$ for 21 hours. Once this pre-charge is concluded, in order to remove the specimens from the autoclave, the temperature needs to decrease to $80^{\circ} \mathrm{C}$ while maintaining the hydrogen pressure. This process has a duration of 1 hour, during which a certain amount of hydrogen egress cannot be avoided. After removing the specimens from the autoclave, they were introduced in liquid nitrogen to avoid further hydrogen losses until the commencement of the fracture tests. The final hydrogen concentration was measured by means of a hydrogen analyser (LECO DH603) using cylindrical specimens $(\cong 20 \mathrm{~g})$ pre-charged at the same time as the SENT specimens. A hydrogen concentration of $4.2 \mathrm{ppm}$ was thus obtained.

Hydrogen cathodic pre-charging was electrochemically applied. A $2 \mathrm{M} \mathrm{H}_{2} \mathrm{SO}_{4}+0,25 \mathrm{~g} / 1 \mathrm{As}_{2} \mathrm{O}_{3}(\mathrm{pH}=1)$ electrolyte under a current density of $2 \mathrm{~mA} / \mathrm{cm}^{2}$ applied for 4 hours was used to introduce the hydrogen in the steel samples. The current density value of $2 \mathrm{~mA} / \mathrm{cm}^{2}$ was adopted based on cathodic polarization test results (Fig. 2a) as the highest value in the Volmer and Heyrovsky region [29,33]. Different pre-charging times $(2,4,15$ and 66 hours) were applied under this current density in order to determine the evolution of hydrogen concentration with pre-charging time. The hydrogen concentration was measured with the aforementioned hydrogen analyser using flat specimens measuring 50x10x $1 \mathrm{~mm}^{3}$. The results showed very small differences among the hydrogen concentration values obtained for 4, 15 and 66 hours $(4.4,4.5$ and $4.3 \mathrm{ppm}$, respectively). In these cases, hydrogen saturation and homogenous hydrogen distribution in the sample was assumed. A cathodic pre-charging time of 4 hours was thus selected as the most suitable.

The values of the average initial hydrogen concentration, $C_{H O}$, for both types of pre-charging methods (gaseous and electrolytic) are shown in Table 4. This table also shows the values of the residual hydrogen irreversibly trapped after a long time at RT (more than 15 days), $C_{H f}$, with the available diffusible hydrogen being calculated as the difference between these two values. Quite similar hydrogen contents were measured in both cases.

Table 4. Initial $\left(C_{H 0}\right)$, final $\left(C_{H f}\right)$ and diffusible $\left(C_{H 0^{-}} C_{H f}\right)$ hydrogen concentration

\begin{tabular}{cccc}
\hline Hydrogen pre-charged condition & $C_{H 0}(\mathrm{ppm})$ & $C_{H f}(\mathrm{ppm})$ & $C_{\mathrm{H}^{-}} C_{\mathrm{H} f}(\mathrm{ppm})$ \\
\hline Gaseous & 4.2 & 4.0 & 0.2 \\
Electrolytic & 4.4 & 4.0 & 0.4 \\
\hline
\end{tabular}

Fracture tests were carried out in air at RT using a MTS testing machine equipped with a $15 \mathrm{kN}$ load cell. A digital image correlation (DIC) system with a $50 \mathrm{~mm}$ Titanar lens was used to enhance the information registered in these tests. The SENT specimens had a length of $125 \mathrm{~mm}$, a width of $25 \mathrm{~mm}$ and a thickness of $1 \mathrm{~mm}$. A distance between grips of $100 \mathrm{~mm}$ was also employed. The applied DIC system required the previous spraying of one of the lateral surfaces of the specimen in order to produce a dotted surface (Fig. $3 \mathrm{~b}-\mathrm{c})$. The use of two cameras allowed the specimen surface to be viewed in 3D throughout the entire test. 
In order to obtain representative $J-R$ curves under each tested condition, the values of the crack length, $a_{i}$, was directly measured during the the test on the surface of the tested specimen based on DIC analysis carried out throughout the test (as can be seen in the example shown in Figure 3.b-c). Due to the small specimen thickness $(1 \mathrm{~mm})$, the same crack length can be assumed through the entire specimen thickness.

Furthermore, the $J$ applied value at any instant, $i$, was calculated using Eq. 3, where: $U_{i}$ is the total area under the load-displacement curve (Figure $3 \mathrm{a}$ ) at this instant; $B$ is the thickness of the specimen $(\cong 1 \mathrm{~mm})$; $b$ is the instantaneous ligament $\left(b_{i}=W-a_{i}\right)$; and $\eta_{i}$ is a dimensionless coefficient that takes into account the influence of the specimen geometry on this general expression.

$$
J_{i}=\frac{\eta_{i} \cdot U_{i}}{B \cdot b_{i}}
$$

\section{RESULTS}

\subsection{Fracture toughness estimation using SENT specimens (without hydrogen)}

Fig. 4a shows the $J-R$ curve obtained using three SENT specimens tested in the absence of hydrogen. The $J$ values represented in this figure were obtained by means of applying Eq. 3 and a value of $\eta_{i}=1$, since the value of this coefficient for this specific specimen geometry is unknown a priori.

Now, the $J$ - $R$ curve obtained using the SENT geometry is compared with that obtained using standard CT specimens (the results obtained with CT specimens are represented in Fig. 4 a as a dashed line, $J=847 \Delta a^{0.71}$ [31]). Note that in order to make this comparison, the SENT $J$ value corresponding to any crack length (red triangles) needs to be corrected by adding the corresponding value of the blunting line (green triangles). This allows fitting the corrected $J-\Delta a$ points to a potential law, $J=638 \cdot \Delta a^{0.43}$ (represented as a continuous line in Fig. 4a). Then, comparing the two fitted curves (CT and SENT), an approximate value of the $\eta_{S E N T}$ coefficient can be estimated as a $\Delta a / W$ function (Fig. $4 \mathrm{~b}$ and Eq. 4 ).

$$
J_{C T}=J_{S E N T} \rightarrow \eta_{S E N T}=\frac{J_{C T}}{J_{S E N T \mid \eta=1}}=\frac{847 \cdot \Delta a^{0.71}}{638 \cdot \Delta a^{0.43}}=1.33 \cdot \Delta a^{0.28} \rightarrow \eta_{S E N T}=3.27 \cdot\left(\frac{\Delta a}{W}\right)^{0.28}
$$

\subsection{Effect of the hydrogen pre-charging method and displacement rate}

The fracture toughness of the hydrogen pre-charged specimens was measured using two different displacement rates, 0.1 and $0.01 \mathrm{~mm} / \mathrm{min}$. The specimen tested without hydrogen and the gaseous precharged specimen under a displacement rate of $0.1 \mathrm{~mm} / \mathrm{min}$ behaved very similarly. However, the cathodically pre-charged specimen showed a significant decrease in fracture toughness, i.e. higher embrittlement (Fig. 5a). On the other hand, the results of the fracture tests carried out under a displacement rate of $0.01 \mathrm{~mm} / \mathrm{min}$ are shown in Fig. $5 \mathrm{~b}$. This figure also shows the fitted curves obtained from the experimental points obtained at $0.1 \mathrm{~mm} / \mathrm{min}$ (Fig. 5a) in order to provide a broader view. Fig. 5b shows a significant decrease in the $J$ fracture parameter for both hydrogen pre-charging methods, although electrolytic pre-charging gave rise to much higher embrittlement indexes.

Table 5 shows the measured fracture toughness values for the different pre-charged conditions (electrolytic and gaseous hydrogen), displacement rates $(0.1$ or $0.01 \mathrm{~mm} / \mathrm{min})$ and crack growths $(0.2,0.5$ and $1.0 \mathrm{~mm})$.

Table 5. Fracture toughness values corresponding to different pre-cracking methods and crack growth (three individual tests were performed in each case)

\begin{tabular}{ccccc}
\hline Condition & $\begin{array}{c}\text { Displacement rate } \\
(\mathrm{mm} / \mathrm{min})\end{array}$ & $\begin{array}{c}J_{0.2^{*}} \\
\left(\mathrm{~kJ} / \mathrm{m}^{2}\right)\end{array}$ & $\begin{array}{c}J_{0.5^{*}} \\
\left(\mathrm{~kJ} / \mathrm{m}^{2}\right)\end{array}$ & $\begin{array}{c}J_{1.0^{*}} \\
\left(\mathrm{~kJ} / \mathrm{m}^{2}\right)\end{array}$ \\
\hline As-received & & $675 \pm 16$ & $1017 \pm 40$ & $1450 \pm 76$ \\
$\mathrm{H}_{2}$ Gaseous & 0.1 & $596 \pm 35$ & $942 \pm 58$ & $1386 \pm 87$ \\
$\mathrm{H}_{2}$ Cathodic & & $197 \pm 87$ & $428 \pm 89$ & $774 \pm 54$ \\
\hline $\mathrm{H}_{2}$ Gaseous & 0.01 & $538 \pm 33$ & $829 \pm 47$ & $1197 \pm 35$ \\
$\mathrm{H}_{2}$ Cathodic & $105 \pm 37$ & $260 \pm 19$ & $513 \pm 54$ \\
\hline
\end{tabular}

*Values calculated with $\eta=3.27(\Delta a / W)^{0.28}$ 
Applying Eq. 2, it was possible to determine the hydrogen embrittlement indexes corresponding to the different tests. Table 6 reveals evident hydrogen embrittlement in the case of the cathodic hydrogen precharging method. However, the embrittlement index corresponding to the gaseous hydrogen pre-charging method was much lower, although a decrease in the test displacement rate always gave rise to an increase in the embrittlement index for both hydrogen pre-charging methods.

Table 6. Hydrogen embrittlement indexes for different pre-charging methods and crack growth (three individual tests were performed in each case)

\begin{tabular}{ccccc}
\hline Condition & $\begin{array}{c}\text { Displacement rate } \\
(\mathrm{mm} / \mathrm{min})\end{array}$ & $\begin{array}{c}\mathrm{HEI}_{0.2} \\
(\%)\end{array}$ & $\begin{array}{c}\mathrm{HEI}_{0.5} \\
(\%)\end{array}$ & $\begin{array}{c}\mathrm{HEI}_{1.0} \\
(\%)\end{array}$ \\
\hline $\mathrm{H}_{2}$ Gaseous & \multirow{2}{*}{0.1} & $12 \pm 5$ & $7 \pm 2$ & $4 \pm 1$ \\
$\mathrm{H}_{2}$ Cathodic & & $71 \pm 21$ & $58 \pm 9$ & $47 \pm 1$ \\
\hline $\mathrm{H}_{2}$ Gaseous & \multirow{2}{*}{0.01} & $20 \pm 10$ & $18 \pm 11$ & $17 \pm 7$ \\
$\mathrm{H}_{2}$ Cathodic & & $84 \pm 11$ & $74 \pm 3$ & $65 \pm 1$ \\
\hline
\end{tabular}

According to the experimental results reported by Peral et al. [31], previously shown in Table $3\left(\mathrm{HEI}_{0.2}\right)$, the CT specimens tested at the lowest displacement rate, $0.01 \mathrm{~mm} / \mathrm{min}$, also presented significant lower embrittlement than the electrolytically pre-charged SENT specimens (33 versus $84 \%$ ).

Fractographic analysis was carried out to identify the operative failure micro-mechanisms. All the analysed surfaces were close to the crack initiation region, as can be seen in Fig. 6a. The specimens tested without hydrogen present characteristic ductile failure (microvoid coalescence micromechanism, MVC, Fig. 6b). On the other hand, the electrolytic pre-charged specimens present wide areas of cleavage micromechanism (decohesion of internal boundaries, HEDE mechanism, Fig. 6d), while the gaseous hydrogen pre-charged specimens show a mixed failure micromechanism (MVC and cleavage), as can be seen in Fig. 6c.

\section{DISCUSSION}

It is nowadays well known that hydrogen embrittlement increases when the triaxiality of the specimen increases (e.g. the presence of notches or cracks) [34]. In this study, we always used cracked specimens under the different testing conditions. The fracture toughness embrittlement indexes of the gaseous hydrogen pre-charged SENT specimens were lower than those determined with CT specimens pre-charged under the same conditions. This finding can be explained by the faster hydrogen losses of the former samples due to their small thickness, $1 \mathrm{~mm}$, as the lower triaxiality of the thin SENT specimen was taken into account by means of the $\eta_{S E N T}$ coefficient. However, when the displacement rate applied in all our tests decreased, embrittlement indexes always increased. Hence, there is still sufficient diffusible hydrogen in the samples to trigger hydrogen embrittlement mechanisms, especially when the test duration is long enough to allow the diffusion of hydrogen to accumulate in the high triaxiality process region existing ahead of the crack tip.

On the other hand, the cathodic pre-charging methodology produced on the SENT geometry much higher hydrogen embrittlement than the gaseous pre-charging method. In the former case, a HEI of $71 \%$ was measured for a displacement rate of $0.1 \mathrm{~mm} / \mathrm{min}$ (for the initiation of crack growth, $0.2 \mathrm{~mm}$ ). Moreover, when the displacement rate decreased tenfold $(\mathrm{v}=0.01 \mathrm{~mm} / \mathrm{min})$, a hydrogen embrittlement index of $84 \%$ was obtained.

In order to explain all these results, it is important to take into account the diffusible hydrogen concentration provided by the two pre-charging methods, which is the hydrogen able to move in the process zone to promote the embrittlement. As already shown in Table 4, the initial hydrogen concentration $\left(C_{H O}\right)$ measured in the case of the gaseous pre-charge is somewhat lower than that measured after cathodic pre-charging. The final concentration (irreversible trapped hydrogen, $C_{H f}$ ) in the steel is similar in both cases. Thus, the diffusible hydrogen is higher in the case of cathodic pre-charging ( $0.4 \mathrm{ppm}$ against $0.2 \mathrm{ppm})$, a fact which could explain the higher HEI obtained in this case. Zhao et al [35] studied the difference between gaseous and electrolytic charging methods using a hydrogen gas pressure of $10 \mathrm{MPa}$ at $85^{\circ} \mathrm{C}$ for 96 hours and $1 \mathrm{~N}$ $\mathrm{H}_{2} \mathrm{SO}_{4}$ electrolyte with $0.25 \mathrm{~g} / 1 \mathrm{As}_{2} \mathrm{O}_{3}$ for 3 hours under a current density of $10 \mathrm{~mA} / \mathrm{cm}^{2}$ on a ferriticpearlitic low alloyed steel. These authors measured a much greater hydrogen content after the electrolytic charging. It is also worth noting that hydrogen fugacity associated to electrolytic pre-charging is usually much greater than can be obtained in hydrogen gas [36]. 
In our study, gaseous pre-charging was carried out by introducing the specimens into the reactor for a very long time at high temperature but, once this pre-charge was concluded, in order to remove the specimens from the autoclave, it was necessary to decrease the temperature to $80^{\circ} \mathrm{C}$ and during this phase the thin SENT specimen experiment a significant loss of hydrogen. On the other hand, any hydrogen loss occurs since the end of the precharge and the start of the mechanical test in the case of the electrolytically precharged specimens. Then, assuming that the initial average hydrogen concentration $\left(C_{H O}\right)$ could be similar regardless of the pre-charging method employed (Table 4), the local hydrogen concentration near the crack tip at the surface of the cathodically pre-charged specimens would be higher than that in the gaseous precharged specimens, being sufficient in this case to reach the critical hydrogen concentration and trigger hydrogen embrittlement mechanisms [37].

Strain values at any point on a specimen surface were also obtained by means the DIC method. Thus, the evolution of the strain on the crack front ligament in the course of the test was measured on this way. Figure 7 shows the envelope curve of these deformation measurements for the two types of hydrogen pre-charging methods and also for the as-received material (without hydrogen). It is worth noting that the gaseous precharged specimens attained close to or slightly higher strain values than those of the as-received specimens. However, the cathodically pre-charged specimens needed lower local strain values to trigger crack growth.

The higher strain values for crack growth needed for the gaseous pre-charged samples would indicate the development of greater plasticity and hence the prevalence of a HELP (hydrogen enhanced localized plasticity) mechanism, the presence of hydrogen facilitates the movement of dislocations, and a ductile failure process (initiation, growth and coalescence of microvoids) predominates, although some HEDE (hydrogen enhanced decohesion) was also observed (some small cleavage regions in Fig. 6c). In accordance with Djukic et al. [38], the lower concentration of hydrogen accumulated in these samples was not sufficient to reach the critical content necessary for a HEDE dominant fracture micromechanism.

On the other hand, the higher average concentration of diffusible hydrogen in the electrochemically precharged specimens $(0.4 \mathrm{ppm}$ versus $0.2 \mathrm{ppm}$, Table 4$)$ allows hydrogen to reach the necessary critical hydrogen concentration in the region ahead of the crack front for the HEDE mechanism to develop. The high local hydrogen concentration existing in the process zone reduced the cohesive strength of internal interphases (martensite lath and packet boundaries) and crack growth takes place under lower local strains $[39,40]$. In this case, a clear change in the failure micromechanism, from microvoids coalescence to a brittle cleavage mechanism took place due to the presence of hydrogen.

It can also be appreciated in Fig.7 that the decrease in the displacement rate decreases the local strain at the crack tip necessary for crack growth. When a lower displacement rate is applied, the hydrogen concentration in the crack tip process zone will increase due to the longer time given to the diffusible hydrogen to move and accumulate in the high triaxiality region at the crack front. Therefore, the cohesive strength in this region will decrease, and the necessary strain values to trigger the fracture micromechanism (HEDE) will also decrease accordingly. This is especially notable in the cathodically pre-charged samples, as diffusible hydrogen content is larger and HEDE micromechanims fully developed.

\section{CONCLUSIONS}

The experimental work reported in this paper enabled us to draw the following conclusions:

The use of SENT specimens has allowed us to characterize the fracture toughness of a CrMoV steel and compare the effect of two different hydrogen pre-charged methods: gaseous hydrogen at high temperature and pressure, and electrolytic pre-charging at room temperature.

The fracture toughness measured using thin SENT specimens was comparable to that determined with standard CT specimens when an appropriate $\eta$ dimensionless coefficient is used.

Electrolytic hydrogen pre-charging gives rise to significantly higher hydrogen embrittlement indexes than gaseous pre-charging, $84 \%$ against $20 \%$ for the initiation of crack growth in fracture toughness tests performed under a low displacement rate of $0.01 \mathrm{~mm} / \mathrm{min}$, mainly due the higher diffusible hydrogen content present on the former samples. This conclusion was further confirmed by differences in the operative fracture micromechanisms observed under the two pre-charging methods: ductile microvoid 
coalescence predominates when hydrogen was pre-charged from a gaseous environment but a brittle, cleavage failure micromechanism was the one observed after electrolytic pre-charging.

The strain evolution ahead of the crack front was also evaluated by means of digital image correlation (DIC) system: significant lower local strain values were needed to trigger crack growth in the cathodically precharged specimens (higher diffusible hydrogen) in comparison with the gaseous pre-charged samples.

Finally, the effect of the displacement rate on the steel hydrogen embrittlement was also quantified: the lower the displacement rate, the higher the hydrogen embrittlement produced, as there is more time for hydrogen to diffuse and accumulate in the process zone ahead of the crack tip.

\section{REFERENCES}

[1] R. P. Gangloff, B. P. Somerday, Gaseous hydrogen embrittlement of materials in energy technologies, 2012. doi:10.1016/0927-5371(94)90021-3.

[2] A.H.S. Bueno, E.D. Moreira, J.A.C.P. Gomes, Evaluation of stress corrosion cracking and hydrogen embrittlement in an API grade steel, Eng. Fail. Anal. 36 (2014) 423-431. doi:10.1016/J.ENGFAILANAL.2013.11.012.

[3] R.A. Siddiqui, H.A. Abdullah, Hydrogen embrittlement in $0.31 \%$ carbon steel used for petrochemical applications, J. Mater. Process. Technol. $170 \quad$ (2005) 430-435. doi:10.1016/J.JMATPROTEC.2005.05.024.

[4] J. Rehrl, K. Mraczek, A. Pichler, E. Werner, Mechanical properties and fracture behavior of hydrogen charged AHSS/UHSS grades at high- and low strain rate tests, Mater. Sci. Eng. A. 590 (2014) 360-367. doi:10.1016/J.MSEA.2013.10.044.

[5] A. Zafra, L.B. Peral, J. Belzunce, C. Rodríguez, Effect of hydrogen on the tensile properties of 42CrMo4 steel quenched and tempered at different temperatures, Int. J. Hydrogen Energy. (2018). doi:10.1016/j.ijhydene.2018.03.158.

[6] A. Zafra, L.B. Peral, J. Belzunce, C. Rodríguez, Effects of hydrogen on the fracture toughness of 42CrMo4 steel quenched and tempered at different temperatures, Int. J. Press. Vessel. Pip. 171 (2019) 34-50. doi:10.1016/J.IJPVP.2019.01.020.

[7] L. Simoni, J.Q. Caselani, L.B. Ramos, R.M. Schroeder, C. de F. Malfatti, The influence of calcareous deposits on hydrogen uptake and embrittlement of API 5CT P110 steel, Corros. Sci. 118 (2017) 178-189. doi:10.1016/J.CORSCI.2017.02.007.

[8] M.A. Arafin, J.A. Szpunar, Effect of bainitic microstructure on the susceptibility of pipeline steels to hydrogen induced cracking, Mater. Sci. Eng. A. 528 (2011) 4927-4940. doi:10.1016/J.MSEA.2011.03.036.

[9] H. Matsunaga, M. Yoshikawa, R. Kondo, J. Yamabe, S. Matsuoka, Slow strain rate tensile and fatigue properties of $\mathrm{Cr}-\mathrm{Mo}$ and carbon steels in a $115 \mathrm{MPa}$ hydrogen gas atmosphere, Int. J. Hydrogen Energy. 40 (2015) 5739-5748. doi:10.1016/J.IJHYDENE.2015.02.098.

[10] H. Xu, X. Xia, L. Hua, Y. Sun, Y. Dai, Evaluation of hydrogen embrittlement susceptibility of temper embrittled 2.25Cr-1Mo steel by SSRT method, Eng. Fail. Anal. 19 (2012) 43-50. doi:10.1016/J.ENGFAILANAL.2011.08.008.

[11] P. Castaño Rivera, V.P. Ramunni, P. Bruzzoni, Hydrogen trapping in an API 5L X60 steel, Corros. Sci. 54 (2012) 106-118. doi:10.1016/J.CORSCI.2011.09.008.

[12] X. Li, J. Zhang, Y. Wang, B. Li, P. Zhang, X. Song, Effect of cathodic hydrogen-charging current density on mechanical properties of prestrained high strength steels, Mater. Sci. Eng. A. 641 (2015) 45-53. doi:10.1016/J.MSEA.2015.06.003.

[13] H. Iwaoka, M. Arita, Z. Horita, Hydrogen diffusion in ultrafine-grained palladium: Roles of dislocations and grain boundaries, Acta Mater. 107 (2016) 168-177. doi:10.1016/J.ACTAMAT.2016.01.069.

[14] R. Thodla, M.T. Piza Paes, B. Gerst, Hydrogen assisted cracking of AISI 4137M steel in O\&amp;G environments, Int. J. Hydrogen Energy. $40 \quad$ (2015) 17051-17064. doi:10.1016/J.IJHYDENE.2015.07.032.

[15] S. Pallaspuro, H. Yu, A. Kisko, D. Porter, Z. Zhang, Fracture toughness of hydrogen charged asquenched ultra-high-strength steels at low temperatures, Mater. Sci. Eng. A. 688 (2017) 190-201. doi:10.1016/J.MSEA.2017.02.007.

[16] G. Álvarez, L.B. Peral, C. Rodríguez, T.E. García, F.J. Belzunce, Hydrogen embrittlement of 
structural steels: Effect of the displacement rate on the fracture toughness of high-pressure hydrogen pre-charged samples, Int. J. Hydrogen Energy. 44 (2019) 15634-15643. doi:10.1016/J.IJHYDENE.2019.03.279.

[17] A. Alvaro, D. Wan, V. Olden, A. Barnoush, Hydrogen Enhanced Fatigue Crack Growth Rates in a Ferritic Fe-3wt\% Si Alloy, Procedia Struct. Integr. 13 (2018) 1514-1520. doi:10.1016/J.PROSTR.2018.12.310.

[18] Q. Liu, A. Atrens, A critical review of the influence of hydrogen on the mechanical properties of medium-strength steels, Corros. Rev. 31 (2013) 85-103. doi:10.1515/corrrev-2013-0023.

[19] G. Rosenberg, I. Sinaiova, Evaluation of hydrogen induced damage of steels by different test methods, Mater. Sci. Eng. A. 682 (2017) 410-422. doi:10.1016/J.MSEA.2016.11.067.

[20] T.E. García, C. Rodríguez, F.J. Belzunce, I. Peñuelas, B. Arroyo, Development of a methodology to study the hydrogen embrittlement of steels by means of the small punch test, Mater. Sci. Eng. A. 626 (2015) 342-351. doi:10.1016/J.MSEA.2014.12.083.

[21] B. Arroyo, J.A. Álvarez, R. Lacalle, Study of the energy for embrittlement damage initiation by SPT means. Estimation of KEAC in aggressive environments and rate considerations, Theor. Appl. Fract. Mech. 86 (2016) 61-68. doi:10.1016/J.TAFMEC.2016.08.019.

[22] T.E. García, B. Arroyo, C. Rodríguez, F.J. Belzunce, J.A. Álvarez, Small punch test methodologies for the analysis of the hydrogen embrittlement of structural steels, Theor. Appl. Fract. Mech. 86 (2016) 89-100. doi:10.1016/J.TAFMEC.2016.09.005.

[23] A. Díaz, J.M. Alegre, I.I. Cuesta, Numerical simulation of hydrogen embrittlement and local triaxiality effects in notched specimens, Theor. Appl. Fract. Mech. 90 (2017) 294-302. doi:10.1016/J.TAFMEC.2017.06.017.

[24] A. Díaz, I.I. Cuesta, J.M. Alegre, A methodology for the numerical assessment of autofrettage influence on hydrogen content near a notch in a 4130 steel pressure vessel, Theor. Appl. Fract. Mech. 92 (2017) 205-213. doi:10.1016/J.TAFMEC.2017.07.024.

[25] B. Meng, C. Gu, L. Zhang, C. Zhou, X. Li, Y. Zhao, J. Zheng, X. Chen, Y. Han, Hydrogen effects on X80 pipeline steel in high-pressure natural gas/hydrogen mixtures, Int. J. Hydrogen Energy. 42 (2017) 7404-7412. doi:10.1016/J.IJHYDENE.2016.05.145.

[26] W. Zhao, T. Zhang, Y. Zhao, J. Sun, Y. Wang, Hydrogen permeation and embrittlement susceptibility of X80 welded joint under high-pressure coal gas environment, Corros. Sci. 111 (2016) 84-97. doi:10.1016/J.CORSCI.2016.04.029.

[27] Y. Wang, J. Gong, W. Jiang, A quantitative description on fracture toughness of steels in hydrogen gas, Int. J. Hydrogen Energy. 38 (2013) 12503-12508. doi:10.1016/J.IJHYDENE.2013.07.033.

[28] E. Fallahmohammadi, F. Bolzoni, G. Fumagalli, G. Re, G. Benassi, L. Lazzari, Hydrogen diffusion into three metallurgical microstructures of a C-Mn X65 and low alloy F22 sour service steel pipelines, Int. J. Hydrogen Energy. 39 (2014) 13300-13313. doi:10.1016/J.IJHYDENE.2014.06.122.

[29] S. Frappart, X. Feaugas, J. Creus, F. Thebault, L. Delattre, H. Marchebois, Study of the hydrogen diffusion and segregation into $\mathrm{Fe}-\mathrm{C}-\mathrm{Mo}$ martensitic HSLA steel using electrochemical permeation test, J. Phys. Chem. Solids. 71 (2010) 1467-1479. doi:10.1016/J.JPCS.2010.07.017.

[30] J. Yamabe, T. Awane, S. Matsuoka, Investigation of hydrogen transport behavior of various lowalloy steels with high-pressure hydrogen gas, Int. J. Hydrogen Energy. 40 (2015) 11075-11086. doi:10.1016/J.JJHYDENE.2015.07.006.

[31] L.B. Peral, A. Zafra, J. Belzunce, C. Rodríguez, Effects of hydrogen on the fracture toughness of $\mathrm{CrMo}$ and $\mathrm{CrMoV}$ steels quenched and tempered at different temperatures, Int. J. Hydrogen Energy. 44 (2019) 3953-3965. doi:10.1016/J.IJHYDENE.2018.12.084.

[32] A. International, ASTM E 1820-01: Standard Test Method for Measurement of Fracture Toughness, 2001. doi:10.1520/E1820-09.2.

[33] H. El Alami, J. Creus, X. Feaugas, Influence of the plastic strain on the hydrogen evolution reaction on polycrystalline nickel electrodes in H2S04, Electrochim. Acta. 51 (2006) 4716-4727. doi:10.1016/J.ELECTACTA.2006.01.012.

[34] R.. Oriani, The diffusion and trapping of hydrogen in steel, Acta Metall. 18 (1970) 147-157. doi:10.1016/0001-6160(70)90078-7.

[35] Y. Zhao, M.-Y. Seok, I.-C. Choi, Y.-H. Lee, S.-J. Park, U. Ramamurty, J.-Y. Suh, J. Jang, The role of hydrogen in hardening/softening steel: Influence of the charging process, Scr. Mater. 107 (2015) 
46-49. doi:10.1016/J.SCRIPTAMAT.2015.05.017.

[36] San Marchi C., Somerday B.P. Sandia Report, SAND2008-1163, Sandia National Laboratory, USA, 2008.

[37] M.B. Djukic, V. Sijacki Zeravcic, G.M. Bakic, A. Sedmak, B. Rajicic, Hydrogen damage of steels: A case study and hydrogen embrittlement model, Eng. Fail. Anal. 58 (2015) 485-498. doi:10.1016/J.ENGFAILANAL.2015.05.017.

[38] M.B. Djukic, G.M. Bakic, V. Sijacki Zeravcic, A. Sedmak, B. Rajicic, The synergistic action and interplay of hydrogen embrittlement mechanisms in steels and iron: Localized plasticity and decohesion, Eng. Fract. Mech. 216 (2019) 106528. doi:10.1016/J.ENGFRACMECH.2019.106528.

[39] R.P. Gangloff, Crack tip modeling of hydrogen environement embrittlement: Application to fracture mechanics life prediction, Mater. Sci. Eng. A. 103 (1988) 157-166. doi:10.1016/00255416(88)90563-0.

[40] S.L. Lee, D.J. Unger, A decohesion model of hydrogen assisted cracking, Eng. Fract. Mech. 31 (1988) 647-660. doi:10.1016/0013-7944(88)90107-5.

\section{Acknowledgments}

The authors would like to thank the Spanish Ministry of Economy and Competitiveness for the funding received to carry out research project RTI2018-096070-B-C31. Authors also thank the financial support received from the Principado de Asturias government through the FC-GRUPIN-IDI/2018/000134 project. Our thanks also to the Scientific and Technical Service, University of Oviedo, for the use of the SEM JEOLJSM5600 scanning electron microscope. 


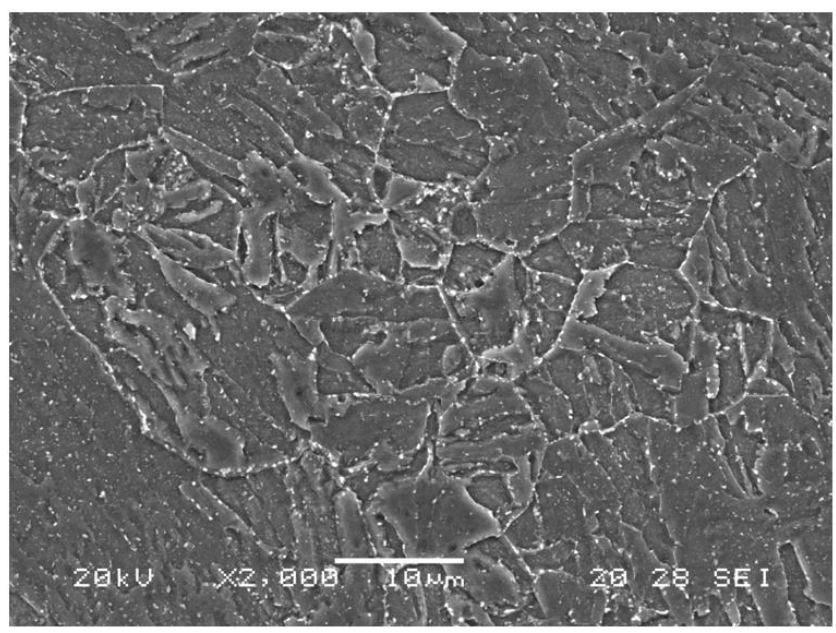

Figure 1. Microstructure of the 2.25CrlMo0.3V steel, 2000x

a)

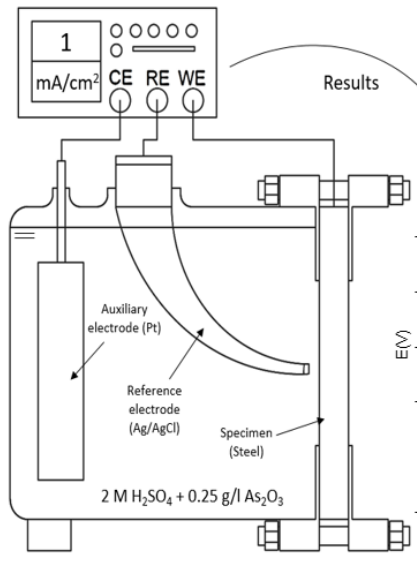

b)

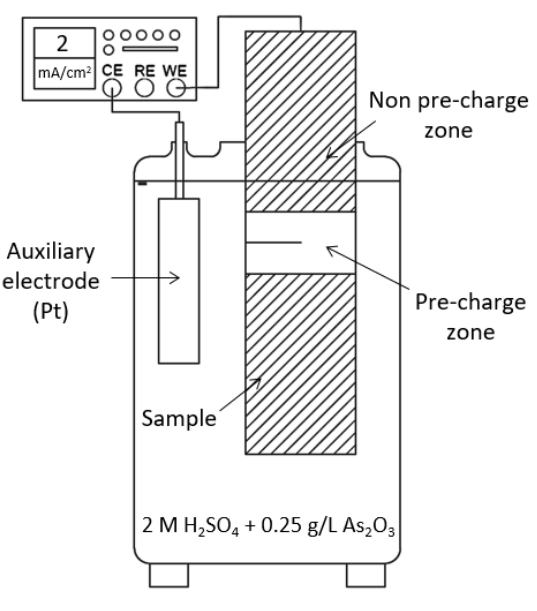

Figure 2. Cathodic pre-charging method: a) cathodic polarization scheme; b) cathodic pre-charge of a SENT specimen 
a)

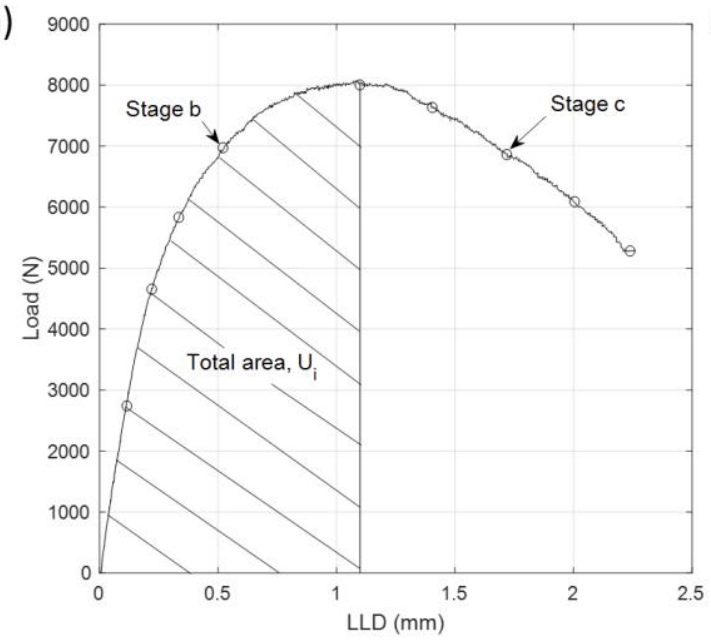

b)

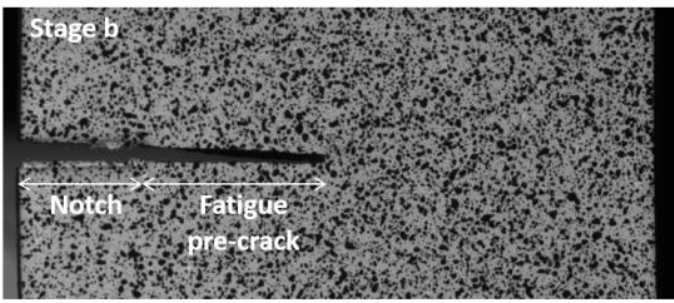

c)

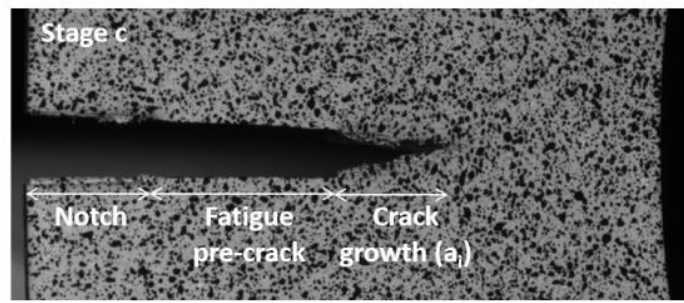

Figure 3. DIC results. a) Load-LLD curve; b) Initial stage of the test; c) Crack growth during the test

a)

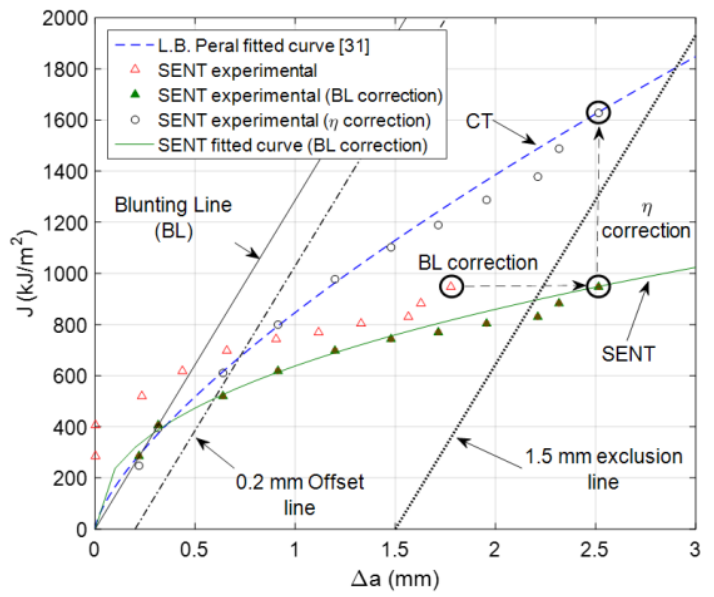

b)

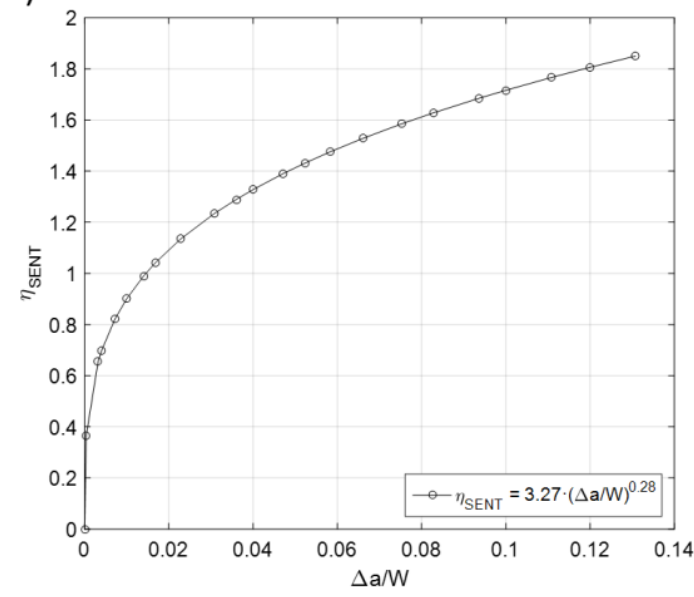

Figure 4. Fracture toughness tests without hydrogen: a) J-R curves for SENT and CT specimens; $b$ ) Relationship between $\eta_{S E N T}$ and $\triangle a / W$. 
a)

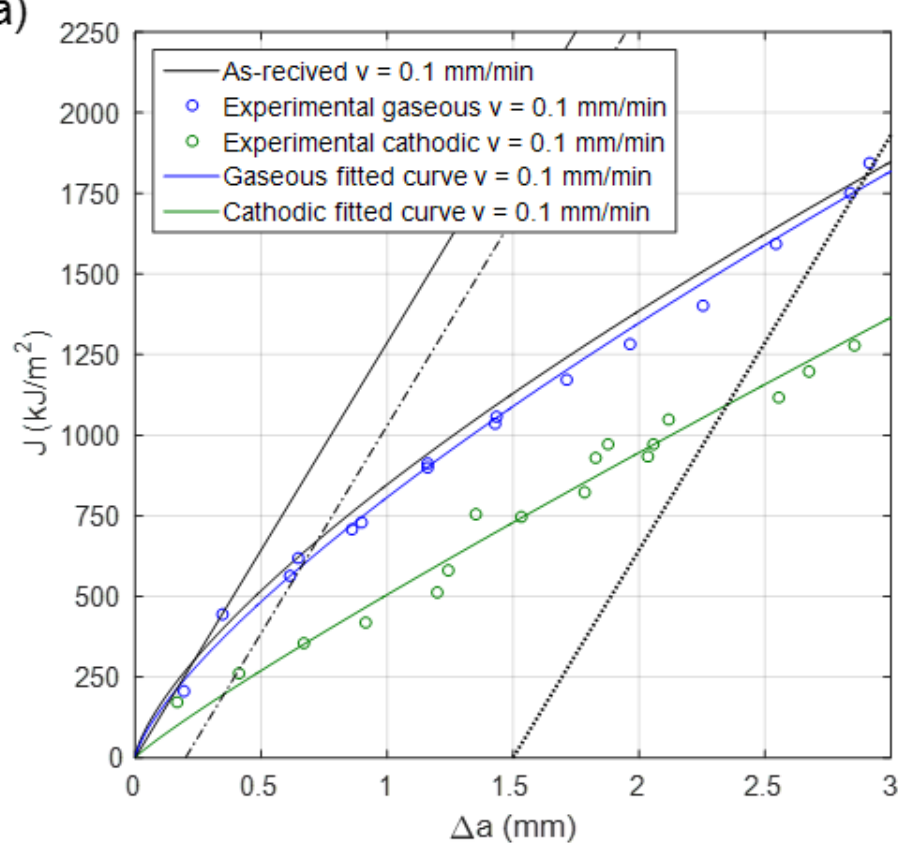

b)

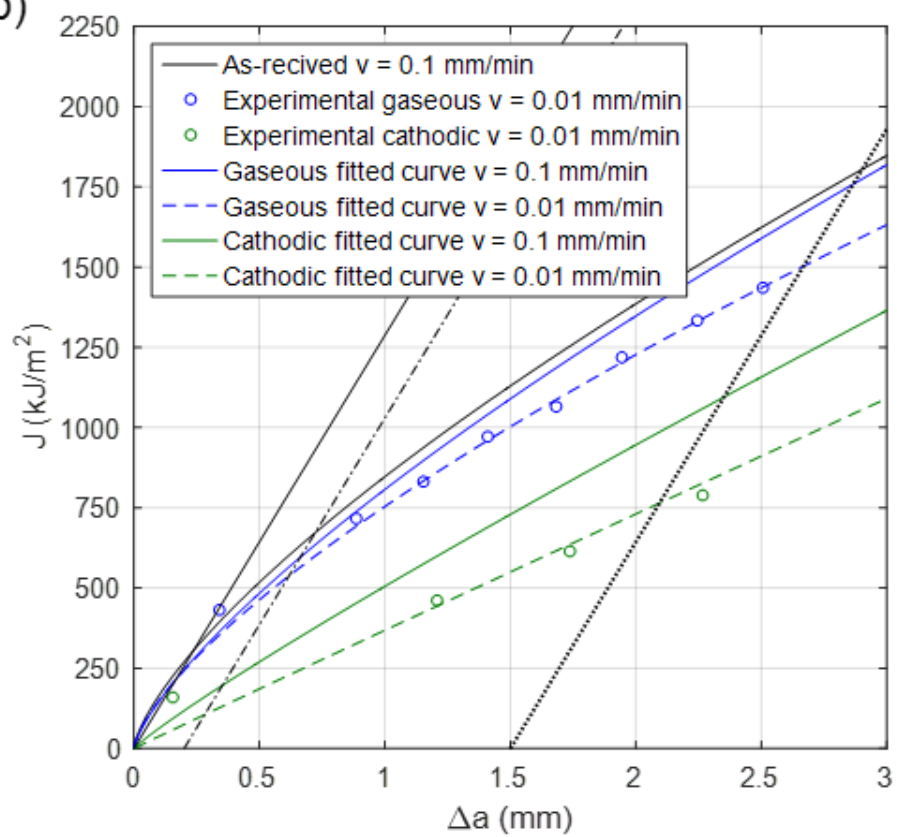

Figure 5. SENT J-R curves (as-received and hydrogen pre-charged specimens): a) $v=0.1 \mathrm{~mm} / \mathrm{min}$; b) $v$ $=0.01 \mathrm{~mm} / \mathrm{min}$ 

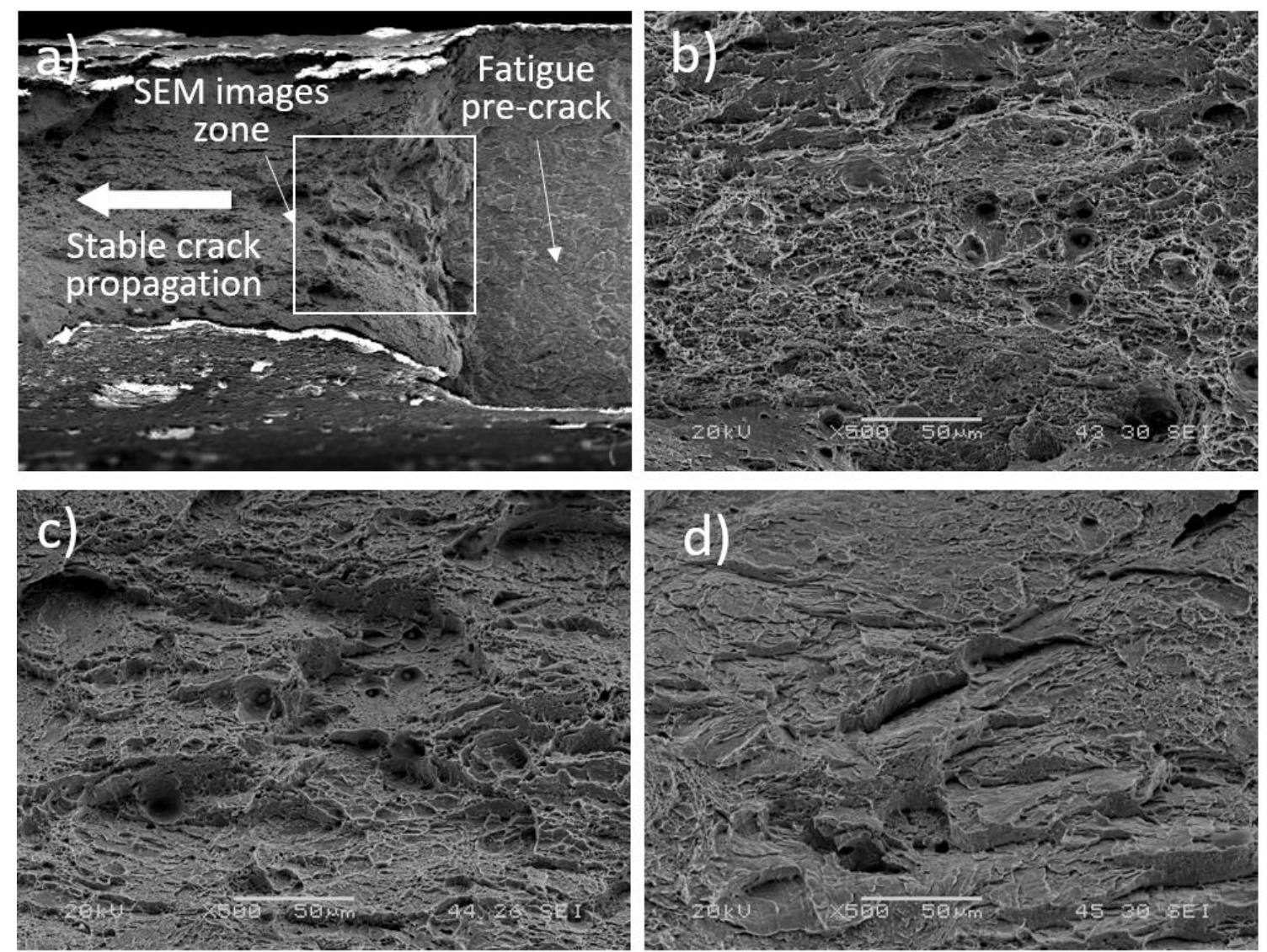

Figure 6. Fracture SENT surfaces: a) General specimen surface view; b) specimen without hydrogen; c) gaseous pre-charged specimen; and d) electrolytic pre-charged specimen.

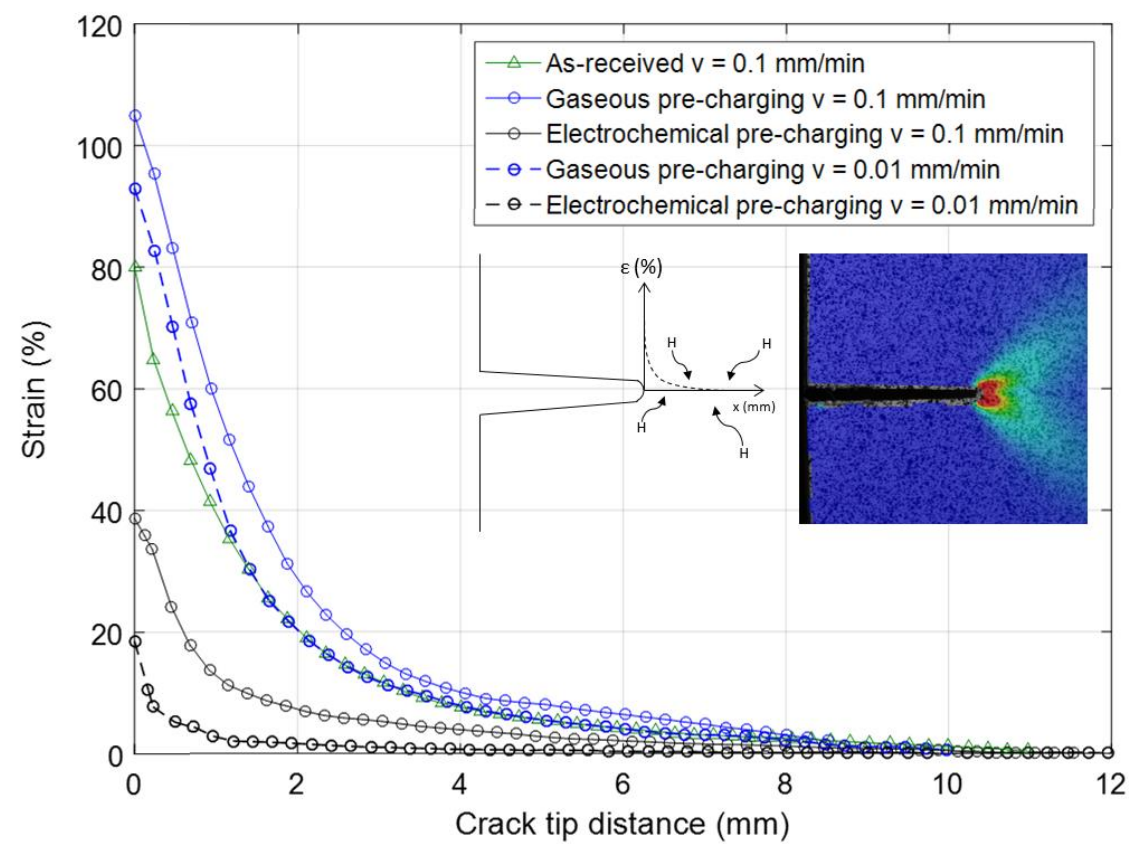

Figure 7. Crack tip strain distribution experimentally measured throughout the fracture toughness tests 